\title{
Conjuring up the correspondence of high-school students' self- determination and classroom climate with reading achievement
}

\author{
Shahrbanoo Joulide a,1,* Akram Faravani* b,2, Ali Akbar Boori ${ }^{\mathrm{b}, 3}$ \\ a, b, c English Department, Islamic Azad University, Razavi Khorasan Province, Mashhad, Kuy-e-Honar, تقاطع; Ostad Yousefi Boulevard, Iran \\ ${ }^{1}$ ahmad58naemi@gmail.com; ${ }^{2}$ afaravani@yahoo.com*; ${ }^{3}$ aaboori@gmail.com \\ * corresponding author
}

ARTICLE INFO

Article history

Received 09 December 2020

Revised 18 December 2020

Accepted 30 December 2020

Keywords

self-determination (SD) self-determination theory classroom climate

reading achievement score motivation

\section{ABSTRACT}

A prevalent goal of education in schools is reading comprehension enhancement. Therefore, a critical issue in educational psychology is investigating the factors contributing to increase the reading achievement including both classroom climate and self-determination. This study explored the relationships of Iranian High School students' self-determination and classroom climate with their reading achievement. 150 Iranian (male and female) students from Sama and Fazele high schools in Mashhad were selected through convenience sampling. The instruments were IOWA self-determination, Classroom Climate Questionnaires, and a validated researcher-made test. It was a type of quantitative and correlational research. Results revealed a significant and positive relationship between self-determination and reading ability. They also showed that among the six subscales of the self-determination, financial management had a significant relationship with the reading achievement scores of students. However, the emotional independence of peers had a negative correlation with the reading achievement scores of students. The results showed that teachers' skill in orienting tasks can enhance reading achievement score and make the classroom climate more motivating. This study has potentially helpful implications for English language teachers, English institutes, and students. Teachers can enhance student's selfdetermination by providing a friendly classroom environment and indirectly boost the students' reading score.

This is an open access article under the CC-BY-SA license.

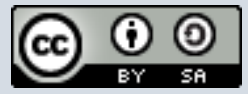

\section{Introduction}

That reading comprehension is delineated from multi aspects and that different professionals in the educational system have concurred on the importance of reading comprehension skill (Calet, Lopez-Reyes, \& Jimenez-Fernandez, 2020; Garner, 1987; Pearson \& Gallagher, 1983; Yu \& Levesque-Bristol, 2020;), seems to lead to the essential point for second language researchers to study the factors that contribute to the enhancement of reading. Technically, reading has been defined as the process of rebuilding meaning from written symbols and so it engages many cognitive processes for comprehension to happen (Durkin, 1978; Perfetti, Landi, \& Oakhil, 2005). Moreover, reading is one of the four skills of language, which deals with understanding vocabulary to interpret the whole meaning of a text. Due to the significance of understanding and interpreting the semantic and syntactic structures of a language as one way to improve one's literacy and as one of the main skills in second or foreign language learning, finding the relationships of any variables which may be somehow related to reading comprehension is of great importance.

Despite many studies that have been conducted in the area of classroom climate (Oostdam, Koerhuis \& Fukkink, 2019; Ranđelović and Dimić, 2020; Wang, Degol, Amemiya, Parr, \& Guo, 
2020), reading comprehension, and self-determination individually, there still seems to be a lack of research to explore the relationships among them in a single study. For instance, Amin (2020) conducted a study on a positive classroom environment and reading comprehension but it lacked the self-determination variable. Several other studies have focused on the relationships between selfdetermination and reading comprehension but lacked the classroom climate variable, including Hornstra, Bakx, Mathijssen, and Denissen's (2020) research that was done from the selfdetermination perspective. Still there are challenges among different scholars in the world and in Iran about the relationships among these three variables. Although a few researches such as Sin and Siahpoosh's (2020); Ahmadi, Namazizadeh, and Mokhtari's (2012); and Khalkhali, Sharifi, \& Nikyar's (2013) study have been conducted, there is still a gap in the studies concerning Iranian high school context. Most of the High School students in Iran have problems in reading comprehension and they, therefore, cannot achieve high scores. This highlights the significance of conducting more studies on the factors that may motivate students to invest more time on reading and gain higher scores.

Among different models in contemporary behavioral sciences, self-determination theory offers a framework or basis for understanding various factors that promote human motivation (Deci \& Ryan, 2002; Gagne \& Deci, 2005; Jang, Kim, \& Reeve, 2016). Self-Determination Theory (SDT) links personality, human motivation, and optimal functioning. It posits that there are two main types of motivation - intrinsic and extrinsic - and that both are powerful forces in shaping who we are and how we behave (Deci \& Ryan, 2002; Gagne \& Deci, 2005). According to Deci and Ryan (2002), extrinsic motivation is a drive to behave in certain ways based on external sources and it results in external rewards. On the other hand, intrinsic motivation comes from within. There are internal drives that inspire us to behave in certain ways, including our core values, our interests, and our sense of morality (Olafsen, Niemiec, Halvari, Deci, \& Williams, 2017). An individual's understanding of his degree of self-determination shows his awareness of needs (Deci, Eghrari, Patrick, \& Leone, 1994). Self- determination theory (SDT) is a macro theory of human motivation and personality that concerns human innate psychological needs (El Miedany et al., 2018). It can be defined that behind every decision that people make there is a kind of self-determination.

As mentioned above, SDT is used in different researches in various fields including psychology, sociology, and education. Many scholars have investigated SDT in educational issues. The importance of these researches is that when teachers try to find ways to promote student's motivation during relatively uninteresting learning activities, they can successfully do so by promoting the value of the task. Research suggests that having high self-determination can foster success in many different domains of life (Roth, Vansteenkiste, \& Ryan, 2019). Self-determination is a key concept in psychology that refers to an individual's ability to make choices and manage his/her own life. Self-determined people feel that they have control over their choices and lives and believe that what they do will affect on the outcome of their actions. Thus, they will be more motivated to take action. However, this concept is not limited to psychology. Self-determination works in many different domains of life including education. Thus, the possibility of a significant contribution of selfdetermination in education and learning justifies the study of a relevant theory in the literature called "self-determination theory". SDT originated from the work of psychologists Edward Deci and Richard Ryan (1985). Self-determination can play an important role in how people function in many different areas of their lives. This theory can help understand the things that might motivate behaviors (Jansen et al, 2020).

Moreover, it has been recognized as one of the most important areas in educational studies (Noels, Lascano, \& Saumure, 2019). If students have a certain level of self-determination, they will make appropriate choices and decisions for their educational life (Liu et al., 2019). Selfdetermination in students leads to organizing and planning for better educational goals. It also increases the problem-solving skills in students and causes positive things to happen in their academic life (Landmark \& Zhang, 2019). In addition, based on SDT, three psychological critical needs should be met to support and facilitate the process of internalization and the development of optimal motivation and to achieve psychological growth. The first need is competence. Competence is defined as the power that leads humans to control the outcome and experiencing mastery. Competency in a learner can be defined as some attitudes, skills, and knowledge that a learner develops and applies for successful learning (Roberts \& Bezuidenhout, 2017). The second innate need is the concept of relatedness which is explained as an emotion that leads humans to be connected to others. 
Research shows that students' relation with the teacher and other students is linked to academic achievement (Guay, Denault, \& Renauld, 2017). The last psychological need that should be met is autonomy. Autonomy can be defined as a desire to be causal agents of one's own life and act in harmony with one's integrated self. Learner autonomy is very useful in the learning process. Learners with autonomy are aware of their weak and strong points. Furthermore, autonomous learners are responsible for their decisions (Fathali \& Okada, 2018). Thus, SDT would be internalized and learners would become autonomously self-determined and motivated when their basic psychological needs are met (Deci \& Ryan, 2002). It seems quite reasonable that intrinsically motivated and autonomous language learners are more actively engaged in their learning.

According to SDT theoreticians, Deci and Ryan (2008), individual personality differences are due to the varying degrees to which each need has been satisfied. Self-determination theory is a key theory in educational and learning contexts since it affects student s' motivation. Motivation will lead to many positive results in learning contexts. The important thing is that teachers and students should be aware of their needs. SDT provides a new vision for language research. Selfdetermination theory also focuses primarily on internal sources of motivation such as a need to gain knowledge or independence which is known as intrinsic motivation (Deci, Olafsen, \& Ryan, 2017). Although self-determination is one of the elements that can guarantee successful learning, classroom climate plays a central role in it as it may predict the satisfaction of basic psychological needs (Alonso-Tapia \& Nieto, 2019). Research has shown that aspects of classroom climate are significantly related to educational motivation. As Creemers and Reezigt (1999) stated that classroom climate influences students' motivation directly.

Classroom climate is defined as the environment including the social, emotional and physical aspects of the classroom. It explains the effects of the teachers on students' behaviors and interactions (Buyse, Verschueren, Verachtert, \& Damme, 2009). Cohen, Pickeral, and McCloskey (2009) define this complex multidimensional construct as the quality and character of school life. Evans et al (2009) define classroom climate as a social psychological construct that is formed through interactions among all agents, the teacher and the students, in the classroom and mediates between these factors. Although there is enough empirical evidence to prove that school climate is a powerful leading external factor which affects students' academic achievement (Brand et al., 2008; Chen \& Weikart, 2008; Collins \& Parson, 2010), the point is that positive classroom climate does not automatically happen, but it is created. This means some things must be done to deliberately shape the climate of the classrooms and change them into positive learning environments. In other words, the way that a teacher is running the classroom should lead to a positive environment.

The first factor in creating a safe supportive positive environment is to develop and reinforce classroom rules and norms. Following rules make students self-regulated and students who have the opportunity to practice self-regulation can focus better on learning. The second factor is promoting positive peer relationships and encouraging positive interactions in classroom contexts. This can be done by paying attention to the social dynamics of the classroom. The last factor is nurturing positive relationships with all students. Using encouraging words in reaction to students' positive behaviors, asking them personal questions to know them, and paying attention to changes in students' physical and emotional behaviors are among a wide variety of techniques that teachers can benefit from to reach this goal. Since a multitude of factors contributes to the overall construct of school climate, researchers have come to the conclusion that this construct is multidimensional in nature. Based on the literature, there are three different dimensions to classroom climate: academic dimension, management dimension, and emotional dimension. The first dimension, the academic dimension, refers to pedagogical and curricular components and elements of the learning environment. Management dimension refers to discipline styles for maintaining order. Emotional dimension refers to the affective interactions within the classroom. The emotional climate examines the interchange of feelings between teacher and students occurring regardless of disciplinary style or degree of control exercised in the classroom (Evans et al., 2009).

Classroom climate is described as a system that is based on four variables: physical setting, organizational aspects, teacher characteristics, and pupil characteristics (Westling-Allodi, 2002). The functions of these variables and the interaction among them constitute the quality of the classroom climate. A positive classroom climate leads to the promotion of students' self-determination and motivational level (Drotar, 2019; Morin, Marsh, \& Nagengast, 2014). Classrooms which do not have a favorable climate cause lack of motivation. The level of teacher support affects the classroom climate (Cheema \& Kitsantas, 2016). The valuable learning outcomes of positive school/classroom 
climate reported in the literature consist of lower dropout rates, higher attendance, increased engagement, deeper learning, improved grades, and improved motivation (Huang, 2003; Lau \& Lee, 2008; Tapola \& Niemivirta, 2008). Good student-teacher rapport guarantees students' feelings of safety and support (Brand, et al., 2003). Moreover, according to Fraser (1994), if a positive classroom climate is created, students will learn better and engage more in learning tasks.

To sum up, classroom climate refers to the emotional and physical aspects of the classroom (Alonso-Tapia \& Nieto, 2019) that can affect students' outcomes and their effective learning. Although there have been various studies on the concept of self-determination, reading ability, and classroom climate, they are still in their early stages. Due to the importance of reading comprehension skill, on one hand, and the ambivalent evidence of the effect of sociocultural context and some psychological traits such as motivation, which is a subcategory of self-determination, on students' learning on the other hand, the present study intended to probe the possible existence of any kind of relationship between self-determination and classroom climate with students' reading achievement scores. Therefore, the following research questions were posed: "Is there any significant relationship between Iranian high school students' self-determination and classroom climate with their reading achievement scores?"

\section{Research Method}

This study intended to examine the relationship of Iranian high school students' selfdetermination and classroom climate with their reading score through a quantitative method. To collect the required data, 150 Iranian high school students (60 Males and 90 Females) with the age range of 15-16 participated in this study. The sampling procedure was convenience sampling. The setting for collecting the required data was the Iranian high schools located in Mashhad city. Two questionnaires were employed including self-determination and classroom climate questionnaires. Moreover, reading scores of the achievement test of students were gathered from the teachers.

Iowa's self-determination questionnaire was designed by Hood and Jackson (1986) to assess the self- determination progress based on Chickering theory (1969). This questionnaire has 90 items and 6 subscales. Each subscale has 15 questions and is based on Likert's five-choice range with questions such as "I know how I treat others, how they treat me". It measures the growth of selfdetermination. The version which was used in this research was the Persian version which has been translated and validated by Selgi and Geramipoor (2020). The reported reliability coefficient for this translated version is 0.99 . In this study, the growth of self-determination refers to the scores that respondents give to the 90 -item questions of the self-determination questionnaire. The questionnaire has 6 subscales: mutual dependence, emotional independence of parents, time management, financial management, emotional independence of peers, and displacement. The research participants were given 15 minutes to complete the questionnaire. The possible range of scores for the IOWA Self-determination questionnaire with 90 items is between 90 and 235 .

The classroom climate questionnaire was introduced by Fraser, Giddings, and McRubby (1995). This questionnaire was translated and validated by Hossienchari and Khayer (2002). In this study, the Persian version of the classroom climate questionnaire translated and validated by Hossienchari and Khayer (2002) was used. Cronbach alpha for reliability of the whole Persian instrument was reported to be 0/87 (Hossienchari \& Khayer, 2002). This questionnaire has 20 items and 4 subscales that are based on a 3-choice Likert scale: seldom, usually, and often. Behrhorst, Sullivan, and Sutherland (2020) considered the classroom climate as a set of environmental characteristics with four dimensions including ecology, culture, environment, and social system. Classroom climate has been known as one of the most effective factors in teaching and learning. The possible range of scores for Classroom Climate questionnaire with 20 items is between 20 and 147. The participants were given 15 minutes to answer the questionnaire. The questionnaire has 4 subscales: unfriendly behavior, cooperation and equality, task orientation and equality, and competition.

Due to the aims of the present study that was investigating the potential relationship between reading achievement score with self-determination and classroom climate, the researcher designed and validated a reading comprehension test based on the level of students. Reading texts were selected from students' work book (Comprehensive English Language Book-10 ${ }^{\text {th }}$ grade). It has 20 multiple-choice questions. The content and face validity of the test was checked by three colleagues. Moreover, to check the reliability of the test with dichotomous items ( 0 and 1 , or one correct answer), KR-20 was used in a pilot study on another group of 30 high school students. The results 
showed that the teat with the rate of .88 is a reliable test with 30 participants in the pilot phase. Besides, the reliability of this test within the main phase of the study was .89 . The learners were given 30 minutes to answer the test.

This study was conducted during the academic year of 2020 in Iranian high schools in Mashhad, a city in the northeast of Iran. The required data was collected by questionnaires of classroom climate and self-determination. At first, participants were asked to fill out the self-determination questionnaire. Then they filled out the classroom climate questionnaire. After the completion of data collection process, the data were entered into SPSS software and the correlations among these three variables were calculated. (SPSS-24) software was employed. To find the answer to research questions 1 and 2, descriptive analysis was used.

\section{Findings and Discussion}

To check the normality of data distribution, the Kolmogorov-Smirnov test was employed. This test is used to check whether the distribution deviates from a comparable normal distribution. If the $p$-value is non-significant ( $p>.05)$, it can be said that the distribution of a sample is not significantly different from a normal distribution; therefore, it is normal. If the $p$-value is significant $(p<.05)$ it implies that the distribution is not normal. Table 1 presents the results of the Kolmogorov-Smirnov test.

Table 1. The Results of Kolmogorov-Smirnov Test

\begin{tabular}{lcc}
\hline & Df & p-value \\
\hline Self-Determination & 131 & .12 \\
Classroom Climate & 131 & .09 \\
Reading Scores & 131 & .06 \\
\hline
\end{tabular}

As can be seen in Table 1, the obtained sig value for all variables is higher than .05 . Therefore, it can safely be concluded that the data is normally distributed across all the variables.

\subsection{Reliability of the Questionnaires}

Table 2 shows the information obtained from Cronbach alpha analyses for two questionnaires.

Table 2. Results of Cronbach Alpha Indexes after Reliability Analysis

\begin{tabular}{ccc}
\hline Scale & Number of items & Cronbach Alpha \\
\hline Self-determination & 90 & .88 \\
Classroom climate & 20 & .72 \\
\hline
\end{tabular}

As the table shows, the utilized questionnaires gained acceptable indexes of Cronbach alpha as a whole: Self-Determination $=.88$, Classroom Climate $=.72$. Cronbach Alpha index for reading Comprehension Test is also acceptable (Reading Comprehension Test $=.89$ )

\subsection{Descriptive Statistics}

Table 3 presents descriptive statistics for the six sub-constructs of self-determination including the mean, standard deviation, maximum and minimum scores. The possible range of scores for all six sub-constructs of self-determination is between 15 and 75 .

As can be seen in Table 3, financial management has the highest mean score (46.97) and the emotional independence of peers has the lowest mean score (42.30). Also, the table shows the number of participants was 150 . 
Table 3. Descriptive Statistics of Sub-Constructs of Self-Determination

\begin{tabular}{|c|c|c|c|c|c|}
\hline & $\mathbf{N}$ & Minimum & Maximum & Mean & Std. Deviation \\
\hline Financial & 150 & 21.00 & 75.00 & 46.97 & 16.66 \\
\hline Management & & & & & \\
\hline $\begin{array}{l}\text { Emotional Independence Of } \\
\text { Parents }\end{array}$ & 150 & 19.00 & 72.00 & 42.33 & 15.17 \\
\hline Emotional & 150 & 21.00 & 69.00 & 42.30 & 12.95 \\
\hline Independence of Peers & & & & & \\
\hline $\begin{array}{l}\text { Mutual } \\
\text { Dependence }\end{array}$ & 150 & 23.00 & 70.00 & 46.12 & 14.67 \\
\hline $\begin{array}{l}\text { Time } \\
\text { Management }\end{array}$ & 150 & 22.00 & 71.00 & 44.76 & 13.43 \\
\hline Displacement & 150 & 22.00 & 75.00 & 46.68 & 17.26 \\
\hline $\begin{array}{l}\text { Self- } \\
\text { determination }\end{array}$ & 150 & 138.00 & 423.00 & 269.19 & 82.45 \\
\hline
\end{tabular}

Table 4 presents descriptive statistics of sub-constructs of classroom climate. The possible range of scores for sub-constructs of classroom climate with 5 items is between 5 and 15 .

Table 4. Descriptive Statistics of Students' Classroom Climate

\begin{tabular}{lccccc}
\hline & $\mathrm{N}$ & Minimum & Maximum & Mean & Std. Deviation \\
\hline $\begin{array}{l}\text { Unfriendly } \\
\text { Behaviour }\end{array}$ & 150 & 5.00 & 15.00 & 8.90 & 2.43 \\
$\begin{array}{l}\text { Task Orientation } \\
\text { and Equity }\end{array}$ & 150 & 5.00 & 15.00 & 10.15 & 2.82 \\
$\begin{array}{l}\text { Cooperation and } \\
\begin{array}{l}\text { Equality. } \\
\text { Competition }\end{array}\end{array}$ & 150 & 5.00 & 15.00 & 9.68 & 2.95 \\
\hline
\end{tabular}

As can be seen in Table 4, unfriendly behavior has the lowest mean score (8.90) and task orientation and equity have the highest mean score (10.15).

Table 5 presents descriptive statistics of students' reading ability. The possible range of scores for this test is between 0 and 20 .

Table 5. Descriptive Statistics of Students' Reading Score

\begin{tabular}{cccccc}
\hline & N & Minimum & Maximum & Mean & Std. Deviation \\
\hline Reading Score & 131 & 7.00 & 20.00 & 14.23 & 3.04 \\
\hline
\end{tabular}

As can be seen in Table 5, the minimum score for Reading Score is 7 and the maximum score is 20. Moreover, the mean score is 14.23 with standard deviation of 3.04 .

\subsection{Main Data Analyses}

\section{Is there any significant relationship between self-determination and Iranian high school students' reading ability?}

To assess the first research question, Pearson correlation was used. Table 6 shows the obtained correlation coefficient related to Iranian high school students' self-determination and their reading ability.

Table 6. Results of Pearson Correlation between Self-Determination and Iranian High School Students' Reading Scores

\begin{tabular}{llc}
\hline & & Reading Scores \\
\hline Self-Determination & Pearson Correlation & $.40^{* *}$ \\
& Sig. (2-tailed) & .00 \\
& $\mathrm{~N}$ & 131 \\
\hline
\end{tabular}


The results of Pearson correlation indicated that there is a positive significant relationship between overall self-determination and reading ability $(r=.40, p<.05)$.

Table 7. Results of Pearson Correlation between Sub-Constructs of Self-Determination and Iranian High School Students' Reading Achievement Scores

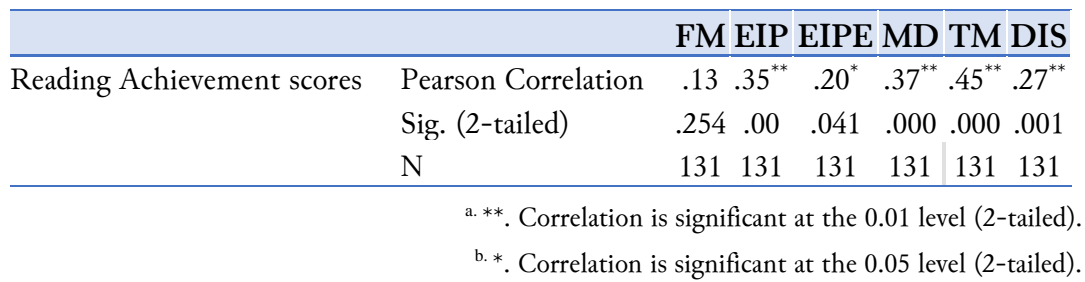

The results of Pearson correlation indicated that among sub-constructs of self-determination, Time Management $(r=.45, p<.05)$ has the highest relationship and Financial Management $(r=.13$, $p<.05)$ has the lowest relationship with reading score.

\section{Is there any significant relationship between the classroom climate and Iranian high school students' reading achievement score?}

To assess the second research question, again Pearson correlation was used. Table 8 shows the results of Pearson correlation between the classroom climate and Iranian high school students' reading ability.

Table 8. Results of Correlation between the Classroom Climate Iranian High School Students' Reading Achievement Scores

\begin{tabular}{llcccc}
\hline & & $\begin{array}{c}\text { Unfriendly } \\
\text { Behaviour }\end{array}$ & $\begin{array}{c}\text { Task Orientation and } \\
\text { Equity }\end{array}$ & $\begin{array}{c}\text { Cooperation } \\
\text { and Equality. }\end{array}$ & Competition \\
\hline $\begin{array}{l}\text { Reading } \\
\text { Achievement }\end{array}$ & $\begin{array}{l}\text { Pearson } \\
\text { Correlation }\end{array}$ & -.10 & $.46^{* *}$ & $.29^{*}$ & $.33^{* *}$ \\
scores & Sig. (2-tailed) & .220 & .000 & .000 & .001 \\
& $\mathrm{~N}$ & 131 & 131 & 131 & 131 \\
\hline
\end{tabular}

The results of Pearson correlation indicated that among sub-constructs of classroom climate, Task Orientation and Equity $(r=.46, p<.05)$ has the highest relationship. Unfriendly Behavior $(r=-$ $.10, p>.05$ ) has the lowest relationship with reading ability. As stated before, the main purpose of the present study was to explore the relationship between classroom climate and self-determination with the reading ability of Iranian students. To investigate the potential relationship, the researcher used quantitative data.

Regarding the relationship between self-determination and reading ability, findings revealed that there is a significant and positive relationship between self-determination and reading ability. Besides, findings showed that among six subscales of the self-determination, financial management has the highest mean score (46.97) and it has significant relationship with the reading ability of Iranian students and emotional independence of peers has the lowest mean score (42.30) and it has a negative correlation with the reading ability of Iranian students.

This finding is in agreement with Yang, Chiu, Sin, and Lui's (2020) study which was conducted to explore the relationship between self-determination and the academic achievement of students. The results showed that school support has a significant indirect effect on school engagement via self-determination as a mediator. The correlations between school support, self-determination, and school engagement are all positive and significant, whereas peer support did not correlate with school engagement. Moreover, research conducted by Erickson et al. (2015) also unfolds that selfdetermination skills are positively correlated with factors that have been shown to improve academic achievement, one of which can be reading achievement. The obtained significant relationship 
between self-determination and reading score in this study can be due to the fact that selfdetermination enhances students' engagement in reading comprehension.

Also, the finding of the present study agrees with Muir's (2020) study which was conducted in order to investigate the relationship between self-determination and the flipped classroom. The results showed that SDT was an appropriate lens to analyze participants' experiences of the approach, with the teacher being a particularly strong influence on students' motivation for engaging with the approach. Muir's findings also highlight the importance of the role of teachers in creating a learning environment supporting students' self-determination and reading achievement score. Additionally, the observed association between reading ability and self-determination seems to be consistent with Gardner's assertion that the intensity of affective factors like self-determination that is directly related to motivation is a contributing factor to $\mathrm{L} 2$ achievement including reading score and vice versa (Masgoret \& Gardner, 2003). Such contributing environment which lowers the role of inhibiting affective factors can be strengthened by the teachers' qualities in creating a positive classroom environment.

Besides, chances are great that the learners with low sense of self-determination lose their identity and investment and therefore deteriorate in the face of failure. Bogianno and Pittman (1992) advocated that amotivated learners who obviously have lower sense of self-determination tend to use more maladaptive non-effective learning strategies in their courses like reading such as lack of investment and persistence with their tasks which commonly results in decreased performance. Consequently, such learners are not sufficiently diligent to amend the reading strategies in accordance with the demands of the tasks. Also, the present study extends this line of research by investigating the relationships between classroom climate and reading ability. This research showed that there is a positive correlation between two subscales of classroom climate and reading ability. Findings revealed that Task Orientation and Equity $(\mathrm{r}=.46, \mathrm{p}<.05)$ has the highest correlation with Iranian students' reading ability and unfriendly behavior ( $\mathrm{r}=-.10, \mathrm{p}>.05)$ has the lowest correlation with reading ability. The obtained results can be due to the fact that classroom climates that demotivate learners by applying tasks that are not based on their needs and interests or the situations in which the teacher provides a sense of non-equity cause obstacles for them as they fall into a state of helplessness, especially when they see others doing better in the classroom than they are.

As the results showed, equity has a high correlation with reading achievement. This means that supportive and finely classroom environments enhance and so the class becomes more enjoyable for learners. Furthermore, learners in such environments tend to report a high desire for selfimprovement and motivation for academic achievement (Battistich, Schaps, \& Wilson, 2004; Patrick, Ryan, \& Kaplan, 2007). On the other hand, classroom conditions with strict rules and high teacher control seem to be associated with lower learner engagement and negative feelings about not only the classroom but also their success. It appears then that classroom climates that enhance rapport and relationships encourage student motivation and eventually achievement in reading. This finding is in line with Lepola, Lynch, Kiuru, Laakkonen, and Niemi' s (2016) study which was conducted to investigate task orientation as a predictor of grade 3 reading comprehension skills. This study was a five-year longitudinal study. A positive relationship was found between task orientation and reading comprehension of preschool through kindergarten to grade 3. Students are particularly motivated when their teachers provide a learning environment with challenging and meaningful tasks. Therefore, as the results of the present study unfolded, teachers' ability in adapting and adopting tasks may create a motivating environment leading to the enhance ment of selfdetermination and reading score achievement.

Furthermore, the findings of Oostdam, Koerhuis and Fukkink (2019) also are in line with the present study. This study was conducted in order to investigate the maladaptive behavior about the basic psychological needs of students in secondary education. The findings showed significant, negative correlations between maladaptive student behavior in the classroom and the extent to which students' basic psychological needs are met by teachers and fellow students. Both teachers and fellow students play a role in students' maladaptive behavior toward school and withdrawn behavior. When it comes to unfriendly behavior, the perceived support of teachers appears to be particularly relevant, while the role of peers is an important factor in delinquent behavior. Their findings confirm the results of the present study since teachers' skill in considering the students' basic psychological needs makes the classroom environment more fruitful; therefore, students may benefit more from the instruction and classroom environment and achieve higher scores. 


\section{Conclusion}

The present study was an attempt to provide evidence on the relationships of self-determination and classroom climate with the Iranian high school students' reading achievement score. The present study demonstrated that time management, which is one of the subscales of self-determination, has the highest correlation with the reading comprehension and that task orientation, which is one of the subscales of classroom climate, has the highest positive correlation with reading ability, while unfriendly behavior has a small negative correlation with it. In general, from the findings it can be concluded that self-determination and classroom climate have an undeniable effect on the Iranian high school performance level of reading achievement. In other words, to have students with higher reading ability, teachers should help students to increase self-determination. The best strategy for teachers in this regard is to teach students some valuable techniques to improve their time management. Another significant factor that can help education authorities to have students with higher reading ability is managing their classroom climate. This pedagogical goal can be best achieved through implementing some strategies to manage classroom climate in a task-oriented way.

The findings are potentially helpful for English teachers, English schools or institutes, and students. It provides teachers with some suggestions on how to create more learning opportunities. In addition, recognizing time management as the most correlated sub- construct of students' selfdetermination with their reading ability would encourage English teachers and instructors to manipulate pedagogical strategies to help students to improve their time-management. Besides, realizing that task orientation is the most correlated sub-construct of classroom climate with students' reading ability, teachers can adapt and adopt tasks that motivate students to invest more time on reading achievement. Additionally, If teachers take the results of this study into account, they will teach in a friendly behavior classroom and increase self-determination of their students. Finally, the results recommend English schools or institutes to develop and modify their old policies and renew them in order to increase the performance level of their students and teachers.

This study can open new visions for other studies based on the limitations of the current study. For example, replication of this study can be done in other contexts. The present study addressed students in high schools. Further research can be done to replicate it in universities or institutes. Moreover, the present study only focused on the relationships between self-determination and classroom climate with reading achievement. It is recommended that future researchers conduct correlational studies on other variables related to reading ability. Finally, further studies are suggested to consider various demographic information such as age, gender, and years of study.

\section{REFERENCES}

Ahmadi, M., Namazizadeh, M., \& Mokhtari, P. (2012). Perceived motivational climate, basic psychological needs and self determined motivation in youth male athletes. World Applied Sciences Journal, 16(9), 1189-1195.

Alonso-Tapia, J., \& Nieto, C. (2019). Classroom Emotional Climate: Nature, Measurement, Effects and Implications for Education. Revista de Psicodidáctica (English ed.), 24(2), 79-87.

Amin, F. (2020). Positive classroom environment, cooperative learning strategy, reading comprehension achievement: a correlational study. Language-Edu, 9(1).

Battistich, V., Schaps, E., \& Wilson, N. (2004). Effects of an elementary school intervention on students' connectedness to school and social adjustment during middle school. The Journal of Primary Prevention, 24(3), 243-262. https://doi.org.10.1023/B:JOPP.0000018048.38517.cd

Behrhorst, K. L., Sullivan, T. N., \& Sutherland, K. S. (2020). The impact of classroom climate on aggression and victimization in early adolescence. The Journal of Early Adolescence, 40(5), 689-711.

Brand, S., Felner, R. D., Seitsinger, A., Burns, A., and Bolton, N. (2008). A large scale study of the assessment of the social environment of middle and secondary schools: the validity and utility of teachers' ratings of school climate, cultural pluralism, and safety problems for understanding school effects and school improvement. J. Sch. Psychol. 46, 507-535. https://doi.org.10.1016/j.jsp.2007.12.001

Bogianno, A. \& Pittman, T. (1992). Achievement and motivation. Cambridge: Cambridge University Press. 
Brand, S., Felner, R. D., Shim, M., Seitsinger, A., \& Dumas, T. (2003). Middle school improvement and reform: development and validation of a school-level assessment of climate, cultural pluralism, and school safety. Journal of Educational Psychology 95, 570-588.

Buyse, E., Verschueren, K., Verachtert, P., \& Damme, J. V. (2009). Predicting school adjustment in early elementary school: Impact of teacher-child relationship quality and relational classroom climate. The Elementary School Journal, 110(2), 119-141.

Calet, N., López-Reyes, R., \& Jiménez-Fernández, G. (2020). Do reading comprehension assessment tests result in the same reading profile? A study of Spanish primary school children. Journal of Research in Reading, 43(1), 98-115.

Cheema, J., \& Kitsantas, A. (2016). Predicting high school student use of learning strategies: the role of preferred learning styles and classroom climate. Educational Psychology, 36(5), 845-862.

Chen, G., \& Weikart, L. A. (2008). Student background, school climate, school disorder, and student achievement: an empirical study of New York City's middle schools. J. Sch. Violence 7, 3-20.

https://doi.org.10.1080/15388220801973813

Chickering, A. W., McDowell, J., \& Campagna, D. (1969). Institutional differences and student development. Journal of Educational Psychology, 60(4), 315-326.

Cohen, J., Pickeral, T., and McCloskey, M. (2009). Assessing school climate. Educ. Digest, 74 (8), 45-48

Collins, T. N., and Parson, K. A. (2010). School climate and student outcomes. J. Cross Discipl. Perspect. Educ, 3, 34-39

Creemers, B. P., \& Reezigt, G. J. (1999). The role of school and classroom climate in elementary school learning environments. School climate: Measuring, improving and sustaining healthy learning environments, 30-47.

Deci, E. L., Olafsen, A. H., \& Ryan, R. M. (2017). Self-determination theory in work organizations: The state of a science. Annual Review of Organizational Psychology and Organizational Behavior, 4, 1943.

Deci, E. L., \& Ryan, R. M. (2008). Facilitating optimal motivation and psychological well-being across life's domains. Canadian Psychology/Psychologie canadienne, 49(1), 14-23.

Deci, E. L., \& Ryan, R. M. (1985). Intrinsic Motivation and Self-Determination. Rochester, New York: University of Rochester.

Deci, E. L., \& Ryan, R. M. (2002). Overview of self-determination theory: An organismic dialectical perspective. Handbook of self-determination research, 3-33.

Deci, E. L., Eghrari, H., Patrick, B. C., \& Leone, D. R. (1994). Facilitating internalization: The self-determination theory perspective. Journal of personality, 62(1), 119-142.

Drotar, D. K. (2019). Student-Centered Language Teaching in the East Asian Context (M.A. Thesis).

Durkin, D. (1978). What classroom observations reveal about reading comprehension instruction. Reading research quarterly, 481-533.

El Miedany, Y., Lotfy, H., El Aroussy, N., Mekkawy, D., Nasef, S. I., Hassan, W., ... \& El Gaafary, M. (2018). THU0604 Juvenile inflammatory arthritis: the development and validation of an illustrated questionnaire to measure children's motivation.

Erickson, A. S. G., Noonan, P. M., Zheng, C., \& Brussow, J. A. (2015). The relationship between selfdetermination and academic achievement for adolescents with intellectual disabilities. Research in Developmental Disabilities, 36, 45-54.

Evans, I. M., Shane T. Harvey, S. T., Buckley, L., \& Yan, E. (2009) Differentiating classroom climate concepts: Academic, management, and emotional environments, Kōtuitui: New Zealand Journal of Social Sciences Online, 4(2), 131-146, https://doi.org.10.1080/1177083X.2009.9522449

Fathali, S., \& Okada, T. (2018). Technology acceptance model in technology-enhanced OCLL contexts: A self-determination theory approach. Australasian Journal of Educational Technology, 34(4).

Fraser, B. J. (1994). Research on classroom and school climate. In D. Gabel (Ed.), Handbook of research on science teaching and learning (pp. 493-541). New York: Macmillan. 
Fraser, B. J., Giddings, G. J., \& McRobbie, C. J. (1995). Evolution and validation of a personal form of an instrument for assessing science laboratory classroom environments. Journal of Research in science Teaching, 32(4), 399-422.

Gagné, M., \& Deci, E. L. (2005). Self-determination theory and work motivation. Journal of Organizational behavior, 26(4), 331-362.

Garner, R. (1987). Metacognition and reading comprehension. Norwood, NJ: Ablex Publishing.

Guay, F., Denault, A. S., \& Renauld, S. (2017). School attachment and relatedness with parents, friends and teachers as predictors of students' intrinsic and identified regulation. Contemporary Educational Psychology, 51, 416-428.

Hood, A. B. (1986). Iowa student development instrument. Retrieved April 25, 2002, from Indiana State University: http://garnet.indstate.edu/wbarratt/Dragon/ix/ia-pref.html

Hornstra, L., Bakx, A., Mathijssen, S., \& Denissen, J. J. (2020). Motivating gifted and non-gifted students in regular primary schools: A self-determination perspective. Learning and Individual Differences, 80 , 101871 .

Hossienchari, M. \& Khayer, M. (2002). Investigating the psychosocial atmosphere of the classroom as one of the components of school culture. Journal of Educational Sciences and Psychology, Shahid Chamran University of Ahvaz, 9(4), 25-42

Huang, S. L. (2003). Antecedents to psychosocial environments in middle school classrooms in Taiwan. Learning Environments Research 6, 119-135.

Jang, H., Kim, E. J., \& Reeve, J. (2016). Why students become more engaged or more disengaged during the semester: A self-determination theory dual-process model. Learning and Instruction, 43, 27-38.

Jansen in de Wal, J., van den Beemt, A., Martens, R. L., \& den Brok, P. J. (2020). The relationship between job demands, job resources and teachers' professional learning: is it explained by self-determination theory? Studies in Continuing Education, 42(1), 17-39.

Khalkhali, V., Sharifi, R., \& Nikyar, A. (2013). Students' Intentions to Persist in, Versus Dropout of High School: What Self-determined Motivation Tells Us about It? International Online Journal of Educational Sciences, 5(2).

Landmark, L. J., \& Zhang, D. (2019). Self-determination at a Career and Technical School: Observations of IEP Meetings. Advances in Neurodevelopmental Disorders, 3(2), 152-160.

Lau, K., \& Lee, J. (2008). Examining Hong Kong students' achievement goals and their relations with students' perceived classroom environment and strategy use. Educational Psychology, 28, 357-372.

Lepola, J., Lynch, J., Kiuru, N., Laakkonen, E., \& Niemi, P. (2016). Early oral language comprehension, task orientation, and foundational reading skills as predictors of grade 3 reading comprehension. Reading Research Quarterly, 51(4), 373-390.

Liu, W. C., Wang, C. J., Reeve, J., Kee, Y. H., \& Chian, L. K. (2019). What Determines Teachers' Use of Motivational Strategies in the Classrooms? A Self-Determination Theory Perspective. Journal of Education, 0022057419881171.

Masgoret, A.-M. \& Gardner, R. C. (2003). Attitudes, motivation, and second language learning: A metaanalysis of studies conducted by Gardner and associates. Language Learning, 53, 123-163.

Morin, A. J., Marsh, H. W., Nagengast, B., \& Scalas, L. F. (2014). Doubly latent multilevel analyses of classroom climate: An illustration. The Journal of Experimental Education, 82(2), 143-167.

Muir, T. (2020). Self-determination theory and the flipped classroom: a case study of a senior secondary mathematics class. Mathematics Education Research Journal, 1-19.

Noels, K. A., Lascano, D. I. V., \& Saumure, K. (2019). The development of self-determination across the language course: Trajectories of motivational change and the dynamic interplay of psychological needs, orientations, and engagement. Studies in Second Language Acquisition, 41(4), 821-851.

Olafsen, A. H., Niemiec, C. P., Halvari, H., Deci, E. L., \& Williams, G. C. (2017). On the dark side of work: A longitudinal analysis using self-determination theory. European Journal of Work and Organizational Psychology, 26(2), 275-285. 
Oostdam, R. J., Koerhuis, M. J. C., \& Fukkink, R. G. (2019). Maladaptive behavior in relation to the basic psychological needs of students in secondary education. European Journal of Psychology of Education, 34(3), 601-619.

Patrick, H., Ryan, A. M., \& Kaplan, A. (2007). Early adolescents' perceptions of the classroom social environment, motivational beliefs, and engagement. Journal of Educational Psychology, 99(1), 83-98. https://doi.org/10.1037/0022-0663.99.1.83

Pearson, P. D., \& Gallagher, M. C. (1983). The instruction of reading comprehension. Contemporary educational psychology, 8(3), 317-344.

Perfetti, C. A., Landi, N., \& Oakhill, J. (2005). The Acquisition of Reading Comprehension Skill. In M. J. Snowling \& C. Hulme (Eds.), Blackwell handbooks of developmental psychology. The science of reading: A handbook (p. 227-247). Blackwell Publishing.

Ranđelović, D., \& Dimić, D. (2020). Connection between classroom climate and academic performance. Facta Universitatis, Series: Teaching, Learning and Teacher Education, (1), 083-093

Roberts, J., \& Bezuidenhout, A. (2017). Technology, work roles and competencies of educators facilitating fully or partially via a distance. International Journal of Educational Sciences, 18(1-3), 110-121.

Roth, G., Vansteenkiste, M., \& Ryan, R. M. (2019). Integrative emotion regulation: Process and development from a self-determination theory perspective. Development and psychopathology, 31(3), 945-956.

Selgi L. M., \& Geramipoor, M. (2020). Hanjaryabi va barrasi vizhegihaye ravansanji porseshnameh roshde khodmokhtari Ayova bar asase modelhaye chand arzeshi nazariyeye pasokh-soal. (Norming and Investigating Psychometric Properties of Autonomy Scale Using Polychoromous Item Response Theory Models). Faslname elmi-pazhooheshi ravansanji, 28, 111-126.

Sin, S. L., \& Siahpoosh, H. (2020). Looking at the Impact of the Flipped Classroom Model on Reading Comprehension of Iranian EFL Learners. Arabic Language, Literature \& Culture, 5(2), 14.

Tapola, A., \& Niemivirta, M. (2008). The role of achievement goal orientations in students' perceptions of and preferences for classroom environment. British Journal of Educational Psychology 78, 291-312.

Wang, M. T., Degol, J. L., Amemiya, J., Parr, A., \& Guo, J. (2020). Classroom climate and children's academic and psychological wellbeing: A systematic review and meta-analysis. Developmental Review, 57, 100912.

Westling-Allodi, M. (2002). A two-level analysis of classroom climate in relation to social context, group composition and organization of special support. Learning Environments Research, 5, 253-274.

Yang, L., Chiu, H. M., Sin, K. F., \& Lui, M. (2020). The Effects of School Support on School Engagement with Self-Determination as a Mediator in Students with Special Needs. International Journal of Disability, Development and Education, 1-16.

Yu, S., \& Levesque-Bristol, C. (2020). A Cross-Classified Path Analysis of the Self-Determination Theory Model on the Situational, Individual and Classroom Levels in College Education. Contemporary Educational Psychology, 101857. 